\title{
Probable changes in lake chemistry in Canada's Atlantic Provinces under proposed North American emission reductions
}

\author{
Thomas A. Clair ${ }^{1}$, Ian F. Dennis ${ }^{1}$ and B.J. Cosby ${ }^{2}$ \\ ${ }^{1}$ Environment Canada, Atlantic Region, Sackville, NB, E4L 1G6, Canada \\ ${ }^{2}$ Environmental Sciences Department, PO Box 400123, Clark Hall, University of Virginia, Charlottesville, VA, 22904-4123, USA \\ E-mail for corresponding author: tom.clair@ec.gc.ca
}

\begin{abstract}
Atlantic Canada, located in the extreme north-eastern portion of North America, receives acid precipitation from all major acid emission sources on the eastern part of the continent. The region was glaciated and has thin soils over a generally poorly acid buffering bedrock. Because of regional topography, large groupings of lakes occur in a number of regions. Environment Canada and the Government of New Brunswick have operated lake sampling networks in trend detection studies and have concentrated their work on these lake groupings. The MAGIC model has been applied to these lakes and their catchments to see: a) what initial water chemistry conditions existed before acidification began, b) what the chemistry was like during the worst of regional acid deposition, and c) what it would be like under deposition conditions predicted for new Canadian and US emission reduction proposals. While $\mathrm{pH}$, sulphate, acid neutralisation capacity (ANC) and the sum of the base cations (SBC) of all lakes have been significantly affected by acid deposition, water chemistry conditions are now considerably better than they were in 1975, at the worst of the deposition. However, a 50\% reduction in acid deposition from Year 2000 deposition amounts will not return water chemistry to original conditions in most of the region.
\end{abstract}

Keywords: Atlantic Canada, monitoring networks, acidification, predictions, MAGIC

\section{Introduction}

Because of the region's location in the continental airshed, the Atlantic Provinces of Canada (Atlantic Canada), in the extreme north-eastern portion of North America (Fig. 1), receive acid deposition originating in all the major acid emission zones of North America (Shaw, 1979). Large portions of the region are underlain by a geology with very poor buffering capacity (Shilts, 1981; Clair et al., 2001). Although deposition values are lower than in most of eastern North America, surface water acid neutralisation capacity (ANC) is naturally very low so that acidity can be very high in many of the region's waters (Kerekes, 1974; Kerekes and Freedman, 1989; Clair et al., 1995).

Apart from the low dissolved ion concentrations caused by the poorly weatherable geology, two confounding factors affect the chemistry of waters of this region. Firstly, many lakes are influenced by sea-spray (Watt et al., 1983), which though neutral overall in terms of acidification, can cause temporary imbalances in ANC and acidity (Heath et al.,
1992); these must be taken into account when modelling water chemistry. Secondly, the abundance of wetlands in this region causes high concentrations of natural organic acids (NOAs) that can reduce $\mathrm{pH}$ in these waters (Clair and Freedman, 1986).

To produce realistic estimates of possible changes in the chemistry of surface waters of Atlantic Canada by 2010, predictions for that time of new emission control scenarios are essential. New sulphur dioxide emission targets have been announced by the Canadian and US governments based on commitments under Canada's Post-2000 acid rain Strategy and by the proposed Clear Skies Legislation in the United States. Though the current published reports use different base years, in effect, both countries have agreed to a $50 \%$ reduction in sulphur dioxide emissions by 2010 from 2000 baselines. The effects of the Canadian reductions have been modelled (Kaminski, 2000) and a 62\% reduction in emissions from the 1989 base year has been predicted. This is roughly equivalent to $50 \%$ from the year 2000 . 


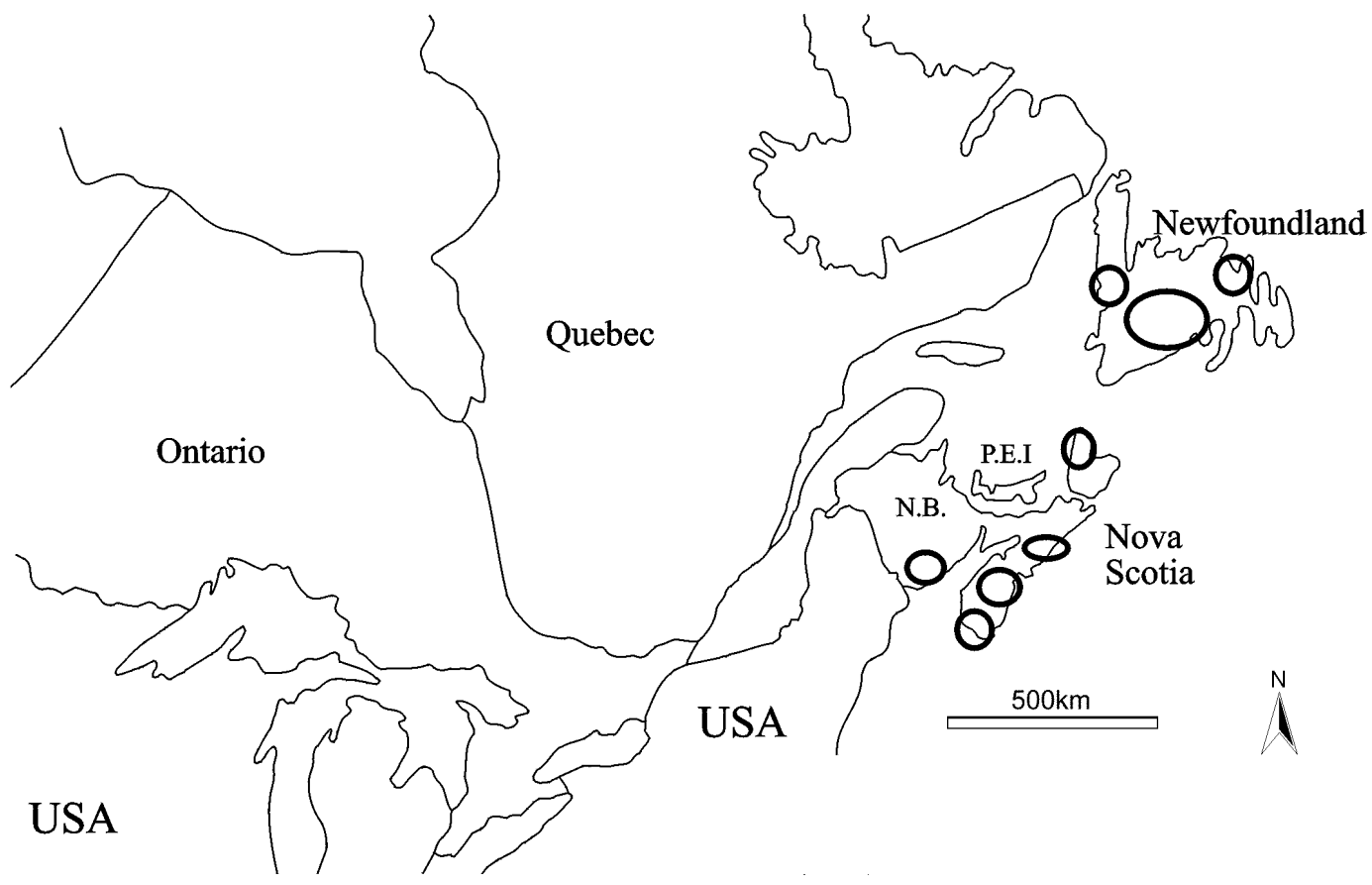

Fig. 1. Location of study area in North America. NS lakes sites are spread out over the Province, but are treated as one group in the analysis.

Though the US emission reductions were not planned jointly with Canada, they produce similar emission reductions. Kaminski (2002) models sulphate deposition in Canada and the northern portion of the US assuming $50 \%$ reductions in both countries. He finds that new deposition reductions will be relatively linear with the changes in North American emissions for the Atlantic Provinces and Ontario in Canada, as well as northern Maine in the US. These relative changes have been adopted in our lake chemistry modelling exercise.

To assess the effect of the proposed changes to acid deposition over the next 10 years on the chemistry of the lakes of Atlantic Canada, the Model of Acidification of Groundwater in Catchments (MAGIC) has been applied to 116 lakes in Federal and Provincial monitoring networks in the region. Model outputs predict the most likely lake water chemistry during pre-industrial times, at the worst acidification period, and in the future under the proposed Canadian and US emission reductions.

\section{Study area}

The portion of Atlantic Canada studied encompasses a region of $260000 \mathrm{~km}^{2}$. The lakes tend to be grouped in areas where topography favours their presence (Fig.1). In 1982-3, Environment Canada began a lake sampling programme twice yearly, in the spring and autumn during overturn periods, to monitor long-term changes in water chemistry in Nova Scotia and Newfoundland. The lakes are sampled by helicopter (Clair et al., 2002) and the samples are analysed by standard methods at the Environment Canada Water Quality Laboratory in Moncton, New Brunswick and at the New Brunswick Department of Environment Laboratory in Fredericton NB. For NB, measurements were averages from Provincial Government surveys in 1995 and 1998

From 1982 to 1999 , total sulphate $\left(\mathrm{SO}_{4}{ }^{-2}\right)$ deposition decreased steadily from 32.4 to $21.4 \mathrm{meq} \mathrm{m}^{-2} \mathrm{yr}^{-1}$ at Kejimkujik National Park in south-central Nova Scotia (NS), from 45.3 to $27.5 \mathrm{meq} \mathrm{m}^{-2} \mathrm{yr}^{-1}$ in southern New Brunswick (NB) and from 21.8 to $14.0 \mathrm{meq} \mathrm{m}^{-2} \mathrm{yr}^{-1}$ in south-eastern Newfoundland (NF) (Clair et al., 2002). In producing forecasts using the MAGIC model, values of deposition were estimated from 1854 to 1982, measured from 1982 to 2000 and, from 2000 to 2010 , decreased linearly by $50 \%$.

The lake catchment geology, soils and plants communities have been described by Clair et al. (2001). The landscape of this entire region was glaciated within the last 16,000 years and soils are, therefore, generally thin. One group of lakes in south-western New Brunswick (NB) (Fig. 1) is underlain by Devonian granites with some Silurian sedimentary rock. Of the four lake groups in Nova Scotia (NS), the three westernmost groups are mostly glacial scour 
lakes located on Devonian granites or Ordovician slates with little acid buffering capacity. Soils are shallow, with mean soil depths of approximately $1 \mathrm{~m}$ (Yanni et al., 2000). The easternmost group of lakes in NS, on Cape Breton Island, lies on a granitic plateau that contains little soil and reflects deposition chemistry quickly. Most of the lakes on the Island of Newfoundland (NF) are in two groups centred in National Parks. The western group of seven lakes is on a bare quartzfeldspar plateau in Gros Morne National Park, the easternmost group of 8 lakes is on siltstone and sandstone terrain in Terra Nova National Park and the remaining 12 lakes are mostly located on Devonian granites in the southern portion of the Island.

The water chemistry as well as recent trends for NS and NF were characterised by Clair et al. (1995, 2002). Median $\mathrm{pH}$ for the NS and NF network lakes from 1994 to 2000 was 5.2 and 6.1 respectively. Median ANC was $2 \mu \mathrm{eq} \mathrm{L} \mathrm{L}^{-1}$ in NS and 34 in NF. Median $\mathrm{SO}_{4}^{-2}$ was twice as high in NS

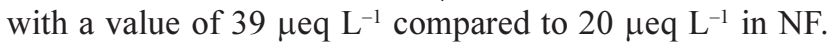
Base cations were also much higher in NF than NS with median $\mathrm{Ca}^{+2}$ equal to $66 \mu \mathrm{eq} \mathrm{L}^{-1}$, compared to 38 in NS. Because of the significant difference in deposition and in water chemistry between the strongly acidified NS and the less acidified NF, the two sets of data were treated separately. The NB sites were also handled separately from the other two as the regional geology differed from NS and NF.

\section{Model Application}

The MAGIC model and its use in 'Regional' mode are described elsewhere in this issue. The model was calibrated for the 116 lakes studied. The lakes in NS and NF were sampled twice yearly from $1982-83$ to the present under the Environment Canada Lake Monitoring Program (Clair et al., 2001), while those in NB were averages from Provincial Government surveys in 1995 and 1998.

Atmospheric deposition inputs were acquired from the Canadian Atmospheric Precipitation Monitoring Network (CAPMoN) sites in Kekimkujik National Park, Nova Scotia and Baie d'Espoir in Newfoundland, as well as from the Government of New Brunswick's South Oromocto Lake Acid Deposition monitoring site. Because of the large area of the present study, mean annual runoff was taken from data reports of the Meteorological Service of Canada. The regional wet deposition estimate was adjusted at each site for dry deposition of anthropogenic pollutants and sea salts using mass-balance calculations based on the stream exports observed.

As implemented in this study, the model is a twocompartment representation of a catchment. Atmospheric deposition enters the soil compartment and the equilibrium equations are used to calculate soil water chemistry. Due to the shallow nature of soils in this region, a one soil layer model configuration was used for all sites. The water was routed to the stream-lake compartment, and the appropriate equilibrium equations are reapplied to calculate runoff chemistry.

Once initial conditions (initial values of variables in the equilibrium equations) were established, the equilibrium equations were solved for soil water and surface water concentrations of the remaining variables. These concentrations are used to calculate the lake discharge output fluxes of the model for the first time step. The mass balance equations were integrated (numerically) over the time step, to provide new values for the total amounts of base cations and strong acid anions in the system. These, in turn, were used to calculate new values of the remaining variables.

Historical simulations for each stream were run using estimates of past deposition based on emissions histories from Canada and from the north-eastern and north-central U.S. which were scaled to the observed current deposition in the study area. The predicted decrease to the year 2010 was then added and that level was maintained into the future, in the absence of any indication of how North American governments may continue emission cutbacks past that period (Fig. 2). Four different time periods were used for water chemistry comparisons and pre-acidification conditions were hindcast for the Year 1875. Estimates of water chemistry conditions in 1975, which was probably the period of greatest deposition in this region provided an idea of the worst-case scenario. The measured depositions from 1997 were used to provide the present day status of

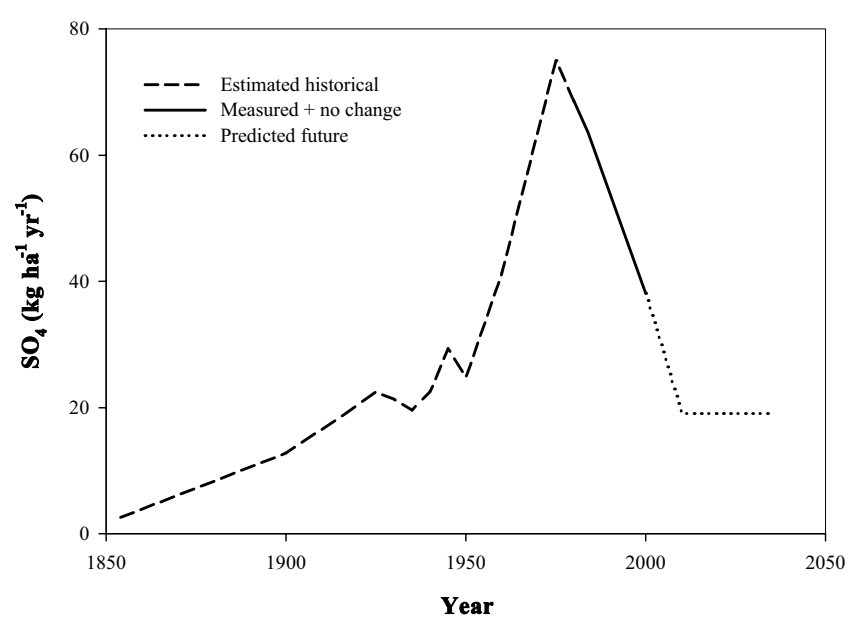

Fig. 2. Acid deposition scenario used in this analysis. Acid deposition is held constant after 2010, as no North American policies are currently in place for post-2010. 
the sites. Finally, water chemistry was predicted for the sites in the year 2016, when most of the Canadian and American emission reductions should be in place.

To show how the three regional lake groups varied under different deposition scenarios, the lake values for $\mathrm{pH}, \mathrm{ANC}$, Sum of the Base Cations ( $\mathrm{SBC}$ ), and $\mathrm{SO}_{4}^{-2}$ were divided into histogram value categories, smoothed using a three category mean average. This provided a much clearer picture of the regional trends in changes in water chemistry; the displays looked more like the normal distributions which would be expected for a group of lakes in any region.

\section{Results and discussion}

The range of data used in the lake calibrations is shown in Table 1. Mean wet $\mathrm{SO}_{4}^{-2}$ concentration in the 1995-97 calibration period ranged from $26.0 \mathrm{meq} \mathrm{m}^{-3}$ in eastern NS to $16.9 \mathrm{meq} \mathrm{m}^{-3}$ at the other extreme of the network range in NF. Historical estimates predicted that at the peak of acid precipitation in 1975 , deposition was probably $50 \%$ greater than during the calibration period. The predicted emission changes will result in a further $50 \%$ reduction from the 1995 97 calibration period.

The hind- and fore-casts show a measurable impact of $\mathrm{SO}_{4}^{-2}$ deposition on water chemistry over the last 100 years and into the foreseeable future. In all regions, water $\mathrm{SO}_{4}^{-2}$ changed over time (Fig. 3). Hindcasting suggests that preacidification modal values were approximately $20 \mu \mathrm{eq} \mathrm{L} \mathrm{L}^{-1}$ in both NB and NS, and slightly lower in Newfoundland at $15 \mu \mathrm{eq} \mathrm{L}^{-1}$. The differences are due to varying sea-salt concentrations which are affected by proximity to the coast as well as by location in relation to wind patterns. In this discussion, the high-valued tails in each of the three regions has been ignored, as they obviously relate to geological sources of $\mathrm{SO}_{4}^{-2}$ such as gypsum and pyritic rocks that are commonly found in the region (Clair et al., 1989).

Under all anthropogenic deposition scenarios, the NB lake sites have the highest $\mathrm{SO}_{4}^{-2}$ values in the region, because of

Table 1. Range of concentration values used in calibrating the models for the different regions of the study area.

\begin{tabular}{|c|c|c|c|c|c|c|c|c|c|}
\hline & & \multicolumn{8}{|c|}{$m e q / m^{3}$} \\
\hline \multicolumn{10}{|c|}{ Precipitation } \\
\hline \multirow[t]{3}{*}{ NS W } & Av & 5.4 & 21.3 & 92.9 & 2.4 & 5.0 & 26.0 & 108.5 & 10.9 \\
\hline & Max & 10.3 & 44.6 & 198.4 & 4.9 & 5.0 & 38.3 & 231.3 & 10.9 \\
\hline & Min & 3.7 & 12.9 & 54.9 & 1.5 & 5.0 & 21.6 & 64.3 & 10.9 \\
\hline \multirow[t]{3}{*}{ NW E } & Av & 5.9 & 24.2 & 107.2 & 2.7 & 3.8 & 24.3 & 124.9 & 7.8 \\
\hline & Max & 7.7 & 33.3 & 148.4 & 3.6 & 5.0 & 28.5 & 172.8 & 10.9 \\
\hline & Min & 3.5 & 12.1 & 50.9 & 1.4 & 3.6 & 20.9 & 59.8 & 7.2 \\
\hline \multirow[t]{3}{*}{ NB } & Ave & 6.3 & 10.2 & 36.1 & 1.8 & 4.9 & 21.2 & 39.7 & 13.0 \\
\hline & Max & 8.3 & 16.7 & 65.3 & 2.6 & 6.3 & 29.0 & 73.2 & 14.3 \\
\hline & Min & 5.6 & 7.5 & 23.7 & 1.3 & 4.7 & 19.0 & 24.8 & 12.8 \\
\hline \multirow[t]{3}{*}{ NF } & Ave & 3.1 & 11.2 & 49.2 & 1.3 & 3.4 & 16.9 & 57.2 & 6.2 \\
\hline & Max & 7.1 & 30.4 & 135.9 & 3.3 & 3.4 & 27.0 & 158.1 & 6.2 \\
\hline & Min & 1.9 & 5.7 & 24.1 & 0.7 & 3.4 & 14.0 & 28.1 & 6.2 \\
\hline \multicolumn{10}{|c|}{ Runoff } \\
\hline \multirow[t]{3}{*}{ NS W } & Av & 38.0 & 42.4 & 151.2 & 7.6 & 0.0 & 52.5 & 149.0 & 0.2 \\
\hline & Max & 91.7 & 100.3 & 310.3 & 15.2 & 0.0 & 106.1 & 331.0 & 0.3 \\
\hline & Min & 10.6 & 21.2 & 94.0 & 3.4 & 0.0 & 22.8 & 90.5 & 0.0 \\
\hline \multirow[t]{3}{*}{ NW E } & $\mathrm{Av}$ & 38.8 & 41.8 & 143.6 & 7.9 & 0.0 & 34.3 & 140.5 & 0.2 \\
\hline & Max & 79.6 & 57.5 & 174.0 & 13.6 & 0.0 & 47.6 & 178.8 & 0.4 \\
\hline & Min & 19.4 & 26.1 & 105.7 & 5.1 & 0.0 & 24.3 & 96.6 & 0.1 \\
\hline \multirow[t]{3}{*}{ NB } & Av & 74.8 & 27.5 & 79.2 & 8.1 & 0.0 & 58.9 & 62.5 & 0.1 \\
\hline & Max & 266.3 & 71.0 & 141.7 & 12.8 & 0.0 & 84.0 & 116.8 & 0.8 \\
\hline & Min & 33.9 & 14.0 & 59.9 & 5.2 & 0.0 & 46.3 & 40.0 & 0.0 \\
\hline \multirow[t]{3}{*}{ NF } & $\mathrm{Av}$ & 51.7 & 25.4 & 75.9 & 5.4 & 0.0 & 24.2 & 68.7 & 0.4 \\
\hline & Max & 122.0 & 55.7 & 184.9 & 10.6 & 0.0 & 60.8 & 189.7 & 1.7 \\
\hline & Min & 15.3 & 11.9 & 41.4 & 2.9 & 0.0 & 14.9 & 33.8 & 0.1 \\
\hline
\end{tabular}



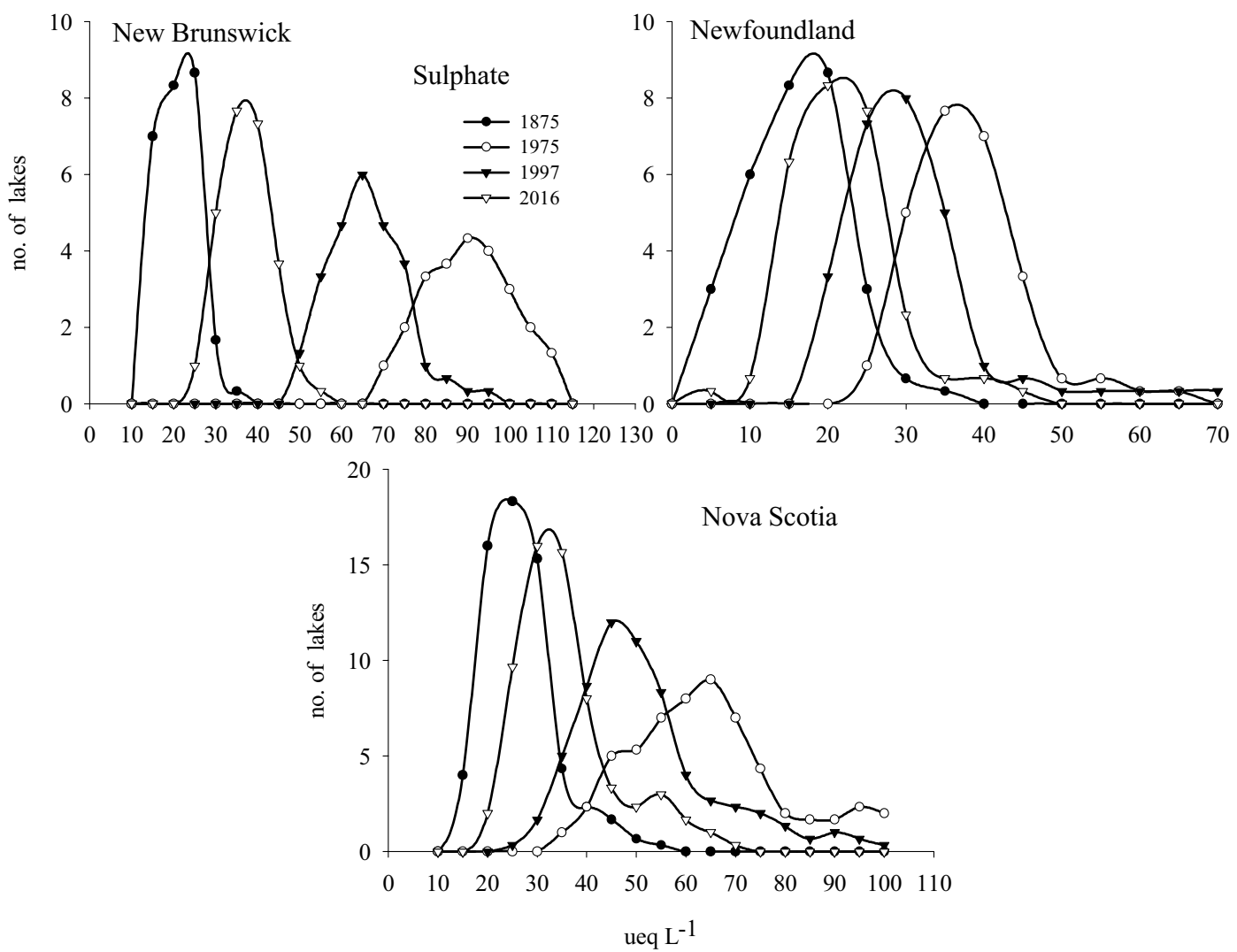

Fig. 3. Sulphate distribution in surface waters of the three study regions. Values are averaged over 3 years.

their greater proximity to central Canadian and north-eastern US emission sources. Under the 1975 worst case scenario, the modal $\mathrm{SO}_{4}^{-2}$ value was $92 \mu \mathrm{eq} \mathrm{L}^{-1}$ in $\mathrm{NB}, 67$ in NS, and $37 \mu \mathrm{eq} \mathrm{L}^{-1}$ in $\mathrm{NF}$, the region furthest from emissions. In 1997, modal $\mathrm{SO}_{4}^{-2}$ values were $65 \mu \mathrm{eq} \mathrm{L}^{-1}$ in NB, 46 in NS, and $27 \mu \mathrm{eq} \mathrm{L}^{-1}$ in NF. Clearly, reductions in lake water $\mathrm{SO}_{4}^{-2}$ have occurred and match those measured in deposition.

The model applications suggest that the proposed emission cutbacks will not return surface water $\mathrm{SO}_{4}^{-2}$ to preacidification levels in NB and NS although in NF, values are almost returned to background. Nevertheless, in all regions, year 2016 predicted modes are closer to 1875 than they are to 1997 (Fig. 3). These results are not surprising, as deposition will not return to pre-acidification levels under this scenario. What needs to be known, however, is whether or not the projected depositions are lower than the critical thresholds which will continue to cause changes in water chemistry.

Under pre-industrial conditions, the NS $\mathrm{pH}$ data show a bimodal distribution with one peak at approximately 5.6 (2.5 $\left.\mu \mathrm{eq} \mathrm{L} \mathrm{L}^{-1}\right)$, and a second at $6.6(0.25 \mu \mathrm{eq} \mathrm{L}-1)$ (Fig. 4). The lower value represents sites, high in natural organic acids (NOAs) and located predominantly in the southeastern portion of the Province. Modelled NB and NF lake mode $\mathrm{pH}$ values are both approximately 6.6 in 1875 , a fairly constant high value for regions little affected by NOAs.

Under the 1975 worst case scenario, a number of interesting phenomena occurred. Firstly, the bimodal $\mathrm{pH}$ distribution in NS disappeared, as lakes with low ANC and high $\mathrm{pH}$ values were overwhelmed by the anthropogenic acids, so that a more 'normal' distribution of values emerged, though with long tails where well buffered lakes are found. The modal value of the NS network lakes was 5.0 (10 $\mu \mathrm{eq}$ $\left.\mathrm{L}^{-1}\right)$, compared to $5.6\left(2.5 \mu \mathrm{eq} \mathrm{L}^{-1}\right)$ earlier. In 1997 after a $50 \%$ reduction in acid deposition from the late 1970 s, the modal value was roughly $5.2\left(6.3 \mu \mathrm{eq} \mathrm{L}^{-1}\right)$ for this region. Predictions for $\mathrm{pH}$ in a post-cut scenario (open triangles) suggest a gradual re-establishment of the bimodal $\mathrm{pH}$ distribution with a peak at $5.4\left(4.0 \mu \mathrm{eq} \mathrm{L}^{-1}\right)$ and another at $\mathrm{pH}$ 6.6. Recovery of $\mathrm{pH}$ to pre-industrial levels will not be complete in the generally south-eastern lakes high in NOAs, but will be close to normal in the western regions. Analysis of the NS pH predictions, therefore, suggests that the lower proposed $\mathrm{SO}_{4}^{-2}$ deposition conditions will not allow acidity to return to pre-acidification levels in all parts of this region. 


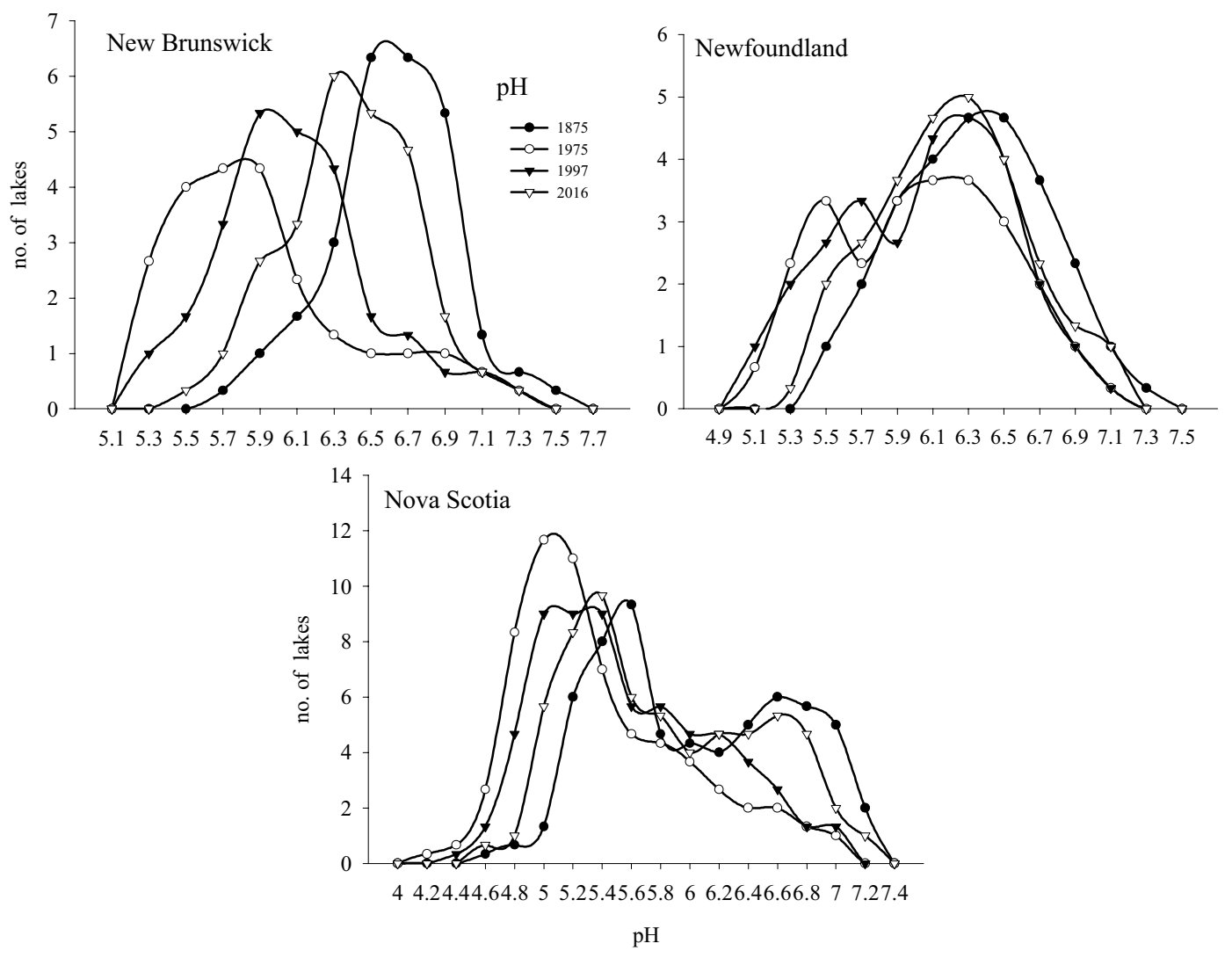

Fig. 4. pH distribution in surface waters of the three study regions. Values are averaged over 3 years.

Oddly, the reverse of the NS situation occurs in NF. An essentially unimodal pre-acidification distribution in 1875 at $\mathrm{pH} 6.4\left(0.4 \mu \mathrm{eq} \mathrm{L}^{-1}\right)$ is converted to a bimodal one in 1975 with peaks at $5.5\left(3.2 \mu \mathrm{eq} \mathrm{L} \mathrm{L}^{-1}\right)$ and $6.2\left(0.63 \mu \mathrm{eq} \mathrm{L}{ }^{-1}\right)$. The lack of an initial bimodal distribution is due to the lesser influence of NOAs in this region. A large number of lakes remain at roughly the same $\mathrm{pH}$ values in 1975 as the preacidification condition. However, a significant number of sites on granitic terrain with little soil in the western portion of NF differ from the rest of the group. The distribution in values remains bimodal in 1997, though there is a general upward shift in $\mathrm{pH}$ from 1975 levels of 5.5 to 5.7 (3.2 to 2.0 $\left.\mu \mathrm{eq} \mathrm{L}^{-1}\right)$ and 6.2 to 6.3 ( 0.63 to $\left.0.5 \mu \mathrm{eq} \mathrm{L}^{-1}\right)$. The modelling predicts an almost complete return to pre-industrial $\mathrm{pH}$ conditions by 2016 under the proposed acid rain emission scenario for this lake set.

In comparison with the other two regions, NB lakes remain in a unimodal distribution under all scenarios, suggesting roughly similar initial buffering capacity for the whole population. The modal $\mathrm{pH}$ value in pre-acidification times, $6.6\left(0.25 \mu \mathrm{eq} \mathrm{L}^{-1}\right)$, drops to $5.8\left(1.6 \mu \mathrm{eq} \mathrm{L}^{-1}\right)$ under the worstcase scenario. By 1997, the lake group mode had recovered to approximately $6.0\left(1.0 \mu \mathrm{eq} \mathrm{L}^{-1}\right)$, and is predicted to move to $6.4\left(0.4 \mu \mathrm{eq} \mathrm{L}^{-1}\right)$ under the 2010 emission scenario, values which are relatively close to pre-acidification. Even under the 1975 scenario, there is a long tail in the higher $\mathrm{pH}$ region showing that a number of lakes in this region remain with relatively unchanging $\mathrm{pH}$.

Ion exchange in soils caused by acidification will increase the export of base cations into streams and lakes. SBC values in the lakes were, therefore, expected to be greatest in 1975, reducing to pre-background levels by 2016 . This was indeed the case. Though the graphs are difficult to interpret properly (Fig. 5), the model nevertheless predicted average SBC increases of $2.9 \%(+/-1.5), 4.0 \%(+/-2.4)$ and $14.2 \%(+/$ - 2.6) in NF, NS and NB respectively from 1875 to 1975 . These increases reflect the amount of acidification stress on the catchments, as well as the underlying geology and soils. The $40-50 \%$ reduction in acidification stress in the region from 1975 values by 1997 caused an average reduction in $\mathrm{SBC}$ concentration in the lake waters to $0.06 \%$ of 1875 levels in NF, $0.6 \%$ in NS, and $5.1 \%$ in NB. Except for NB, SBC levels have, on average, probably returned to pre-acidification levels in the rest of the region. NB lakes have not returned to pre-acidification levels because they are still receiving relatively high amounts of acids and have 


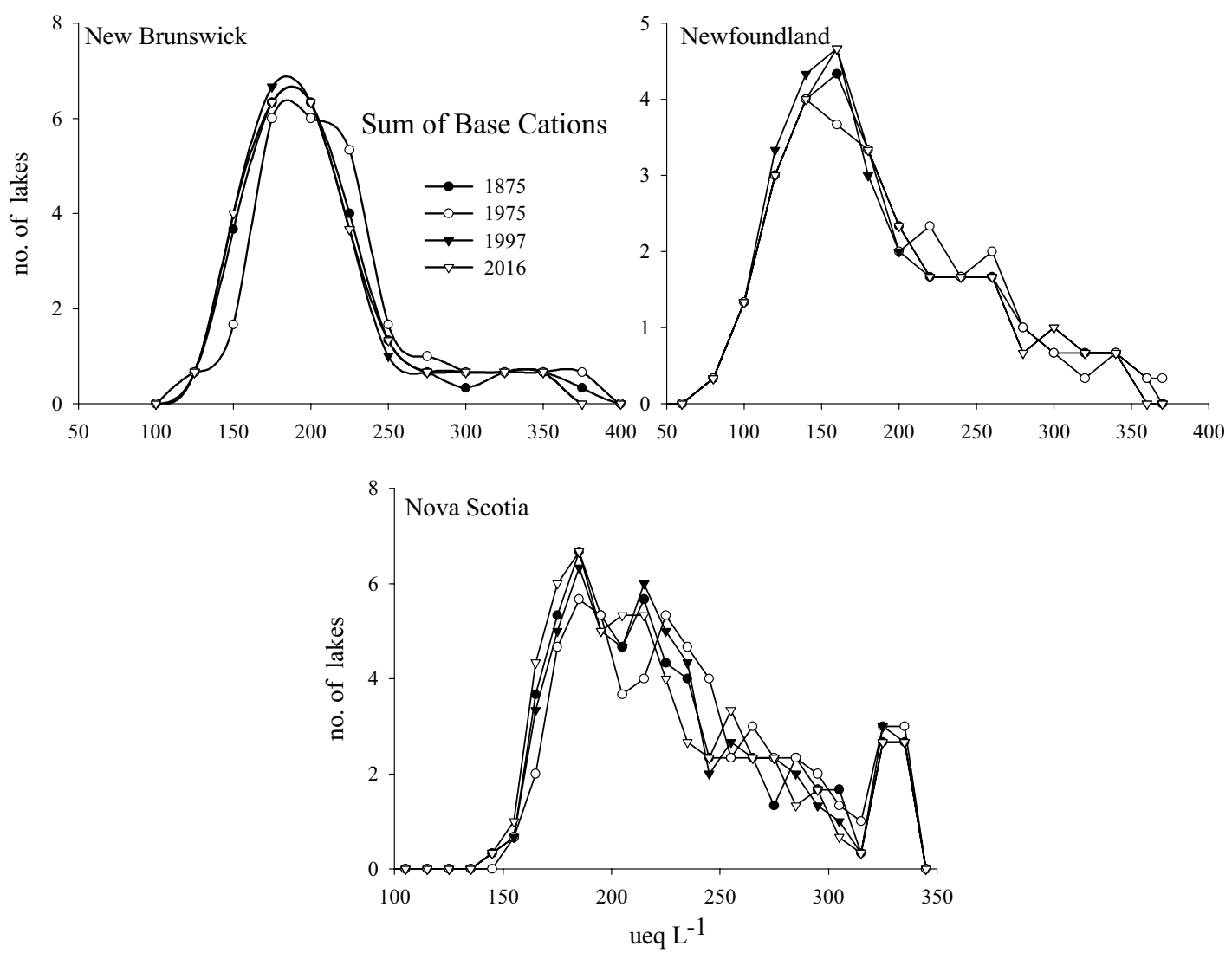

Fig. 5. Sum of Base Cations distribution in surface waters of the three study regions. Values are averaged over 3 years.

soils which still have good buffering capacity.

Analysis of the SBC 2016 model predictions offer an interesting contrast. Lake predictions for all regions suggest that on average, SBC concentrations in 2016, will be somewhat lower than in pre-acidification times. NF values are predicted to be $1.5 \%$ less than pre-acidification conditions $(+/-0.8)$, NS should be $1.4 \%$ less $(+/-0.8)$, and NB $1.6 \%$ less $(+/-0.4)$. These results confirm that the soils in all three regions have been depleted of base cations and that weathering has not kept pace in replenishing soils. Reductions in ion exchange stress will lead to a reduction of cations in water until such a time as bedrock weathering manages to replenish soil ion content. The present results suggest that this will not occur under the emission reductions currently proposed.

The difference between the SBC and the acid anions $\left(\mathrm{SO}_{4}^{-2}\right.$ and $\left.\mathrm{NO}_{3}^{-}\right)$is the ANC. Considering the nonsimultaneous changes found in the acid anion and SBCs, ANC changes were unlikely to be straightforward. As was expected, NF pre-acidification ANC values (ignoring those $>130 \mu \mathrm{eq} \mathrm{L}^{-1}$ ) fitted a bimodal pattern, with peaks at 55 and $95 \mu \mathrm{eq} \mathrm{L} \mathrm{L}^{-1}$. As acidification pressure increased until 1975 , the bimodal pattern remained, but shifted downwards to 40 and $65 \mu \mathrm{eq} \mathrm{L} \mathrm{L}^{-1}$. By 1997, the group with the lower ANC had not changed much from 1975, while the higher ANC group had almost returned to pre-acidification values. By 2016, modelling suggests that the lower ANC group will also return to pre-acidification levels.

The ANC changes expected in NB are more straightforward with only one lake "population" and no bimodal division. NB modal values probably decreased from 105 to $50 \mu \mathrm{eq} \mathrm{L} \mathrm{L}^{-1}$ from 1875 to 1975 and partly recovered

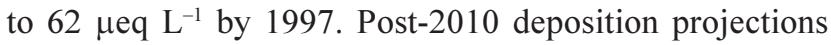
should increase the mode to approximately $85 \mu \mathrm{eq} \mathrm{L}{ }^{-1}$, which still is not back to original levels.

The NS lake mode most likely was reduced from 80 to $52 \mu \mathrm{eq} \mathrm{L} \mathrm{L}^{-1}$ from 1875 to 1975 . Deposition reductions to 1997 seemed to have caused a small shift to a bimodal state where one group of lakes (probably those with lower NOAs) is recovering faster than the other, so that one modal point is at $40 \mu \mathrm{eq} \mathrm{L} \mathrm{L}^{-1}$, while the other is at $62 \mu \mathrm{eq} \mathrm{L}^{-1}$. MAGIC modelling suggests that predicted emission reductions will return ANC much closer to pre-acidification levels with a peak at $72 \mu \mathrm{eq} \mathrm{L^{-1 }}$ and will break down the bimodal distribution. A return to pre-acidification ANC condition will be rapid, because initial conditions were quite low to start with. 


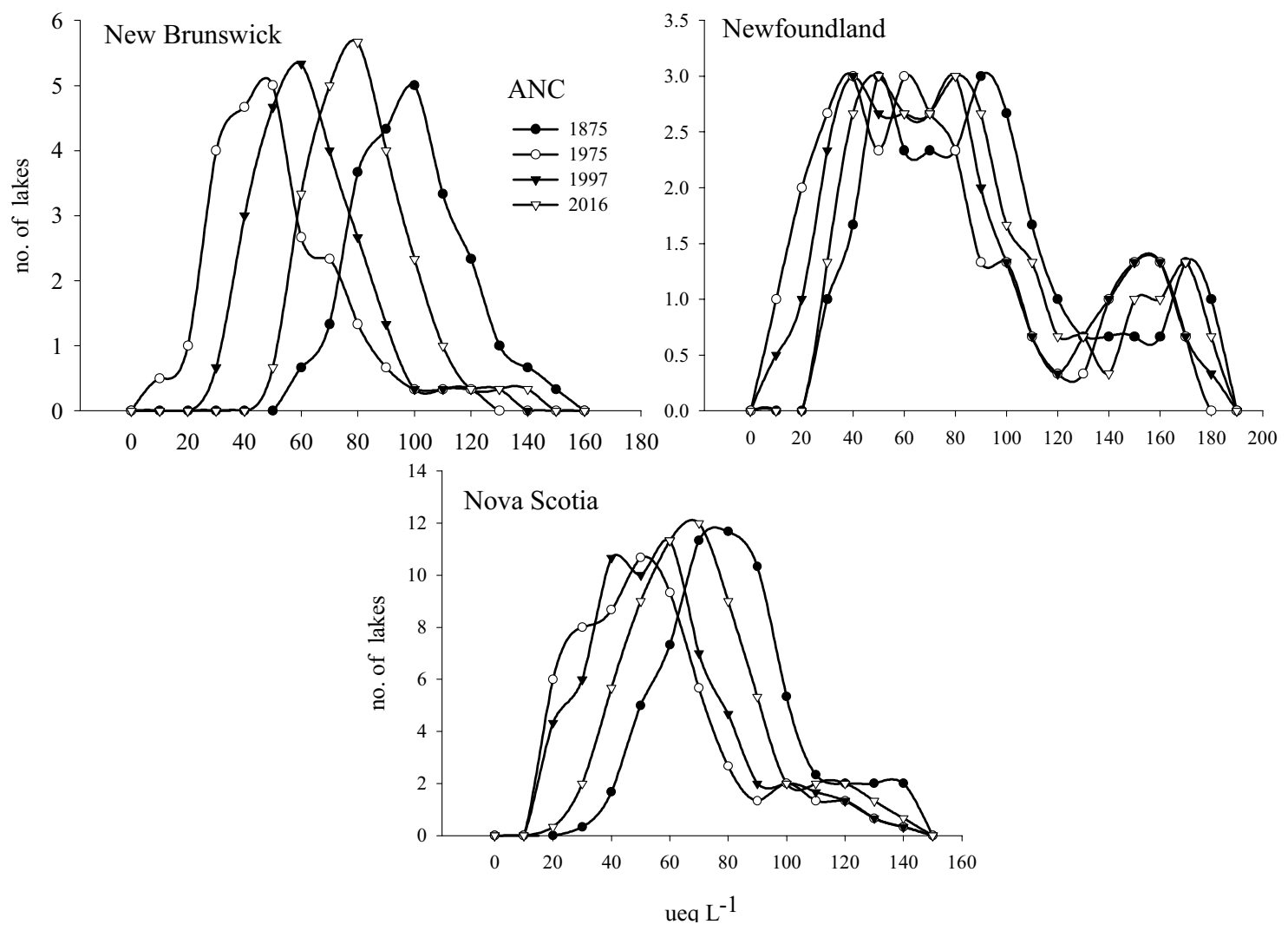

Fig. 6. ANC distribution in surface waters of the three study regions. Values are averaged over 3 years.

\section{Conclusions}

The lakes sampled in Atlantic Canada span a wide area, over several geological types and a large range of acid deposition values. Stratification of the lakes by region clearly assisted in demonstrating regional changes. Nevertheless, all lakes show geochemical reactions to acid precipitation. The area with the lowest $\mathrm{pH}$ values and which are slowest to recover to pre-acidification levels are in Nova Scotia, even though deposition is less there than in New Brunswick. Poorly buffering geology is the main cause of this difference, though the situation is somewhat complicated by the importance of NOAs in affecting $\mathrm{pH}$. Nevertheless, neither NB nor NS will return to pre-acidification $\mathrm{pH}$ conditions under the proposed regime, though major improvements from 1997 values will have been made in the chemistry of lake waters. The Island of Newfoundland is furthest from acid emission sources and shows the least impact and will almost recover to pre-acidification conditions.

\section{Acknowledgments}

The authors thank staff of the New Brunswick Department of Environment and Local Government for providing atmospheric deposition and lake chemistry data for their region. Abbey Ouellet is responsible for the sampling of all the lakes in Nova Scotia. This work was funded by Environment Canada's Acid Rain Program. This work was conducted in part as collaborative research with the Commission of European Communities RECOVER: 2010 project (EVK1-CT-1999-00018)

\section{References}

Clair, T.A. and Freedman, B., 1986. Patterns and importance of dissolved organic carbon in four acidic brownwater streams in Nova Scotia, Canada. Water Air Soil Pollut., 31, 139-147.

Clair, T.A., Schwarcz, H.P. and Kramer, J.R., 1989. The origins of sulfur in waters from four Nova Scotian basins: a stable isotope approach. Appl. Geochem., 4, 93-98.

Clair, T.A., Dillon, P.J., Ion, J., Jeffries, D.S., Papineau, M. and Vet, R.J., 1995. Regional precipitation and surface water chemistry trends in southeastern Canada (1983-91). Can. J. Fisheries Aquat. Sci., 52, 197-212.

Clair, T.A., Lockerbie, D. and Ouellet, A., 2001. Environment Canada's Acid Precipitation Monitoring Networks in Atlantic Canada. Environment Canada - Atlantic Region Report Occasional Report No. 16, CD ROM, Sackville, NB, Canada. 
Clair, T.A., Ehrman, J.M., Ouellet, A.J., Brun, G.L., Lockerbie, D. and Ro, C.-U., 2002. Changes in freshwater acidification trends in Canada's Atlantic Provinces: 1983-1997. Water Air Soil Pollut., 135, 335-354.

Heath, R.H., Kahl, J.S. and Norton, S.A., 1992. Episodic stream acidification caused by atmospheric deposition of sea salts at Acadia National Park, Maine, United States. Water Resour. Res., 28, 1081-1088.

Kaminski, J.W., 2002. Emission-scenario simulations of new Provincial $\mathrm{SO}$, reduction targets using the acid deposition and oxidation model. Contract Report prepared for the Canadian Council of Ministers of the Environment, Winnipeg, Manitoba, Canada.

Kerekes, J.J., 1974. Limnological conditions in five small oligotrophic lakes in Terra Nova National Park, Newfoundland. $J$. Fisheries Res. Board Can., 31, 555-583.
Kerekes, J.J. and Freedman, B., 1989. Characteristics of three acidic lakes in Kejimkujik National Park, Nova Scotia, Canada. Arch. Environ. Contam. Toxicol., 18, 183-200.

Shaw, R.W., 1979. Acid precipitation in Atlantic Canada. Environ. Sci. Technol., 13, 406-411.

Shilts, W.W., 1981. Sensitivity of bedrock to acidification: modification by geological processes. Geological Survey of Canada, Paper 81-14.

Watt, W.D., Scott, C.D. and White, J.W., 1983. Evidence of acidification of some Nova Scotia rivers and its impact on Atlantic salmon, Salmo salar. Can. J. Fisheries Aquat. Sci., 40, 462-473.

Yanni, S., Keys, K., Clair, T.A. and Arp, P.A., 2000. Fog and acidification impacts on ion budgets of basins in Nova Scotia, Canada. J. Amer. Water Resour. Assoc., 36, 619-631. 